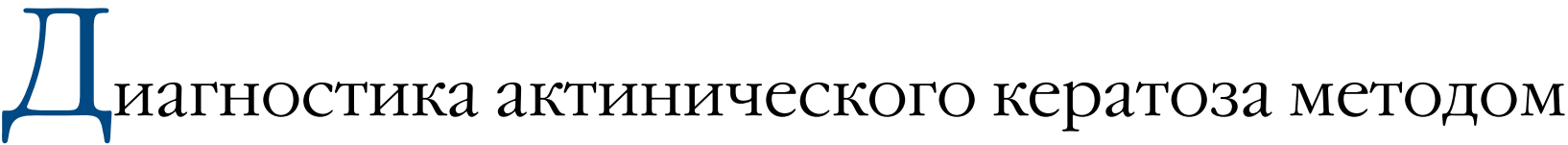 дерматоскопии
}

\author{
А. Н. Хлебникова ${ }^{1}$, К. В. Обыденова ${ }^{2}$ Т. Г. Седова ${ }^{3}$, В. В. Андрюхина ${ }^{2}$ \\ 1 ФГАОУ ВО Первый МГМУ им. И. М. Сеченова Минздрава России (Сеченовский университет) \\ 119991, г. Москва, ул. Трубецкая, д. 8, стр. 2 \\ 2 ГБУЗ МО МОНИКИ им. М. Ф. Владимирского \\ 129110 , г. Москва, ул. Щепкина, д. 61/2 \\ 3 ГБОУ ВПО ПГМУ им. академика Е. А. Вагнера \\ 614000, г. Пермь, ул. Петропавловская, д. 26
}

Актинический кератоз (АК) является локальной внутриэпидермальной атипией кератиноцитов, образующейся вследствие интенсивного и длительного воздействия солнечных лучей. Очаги АК располагаются на открытых участках кожного покрова, в основном на лице, в связи с этим более актуальны неинвазивные методы диагностики, в первую очередь дерматоскопия.

Материал и методы. Было обследовано 35 пациентов и выявлено у них 204 очага.

Результаты. Среди 204 очагов эритематозная форма встречалась в 160 (78,4\%) случаях, кератотическая — в 24

(11,8\%), пигментная - в 20 (9,8\%). У пациентов с АК наиболее частыми дерматоскопическими признаками явились эритема (90,2\%), сосудистые структуры (67,65\%), кератиновые чешуйки (51,47\%), псевдосетка $(23,04 \%)$.

обсуждение. При анализе дерматоскопической картины наиболее частых форм АК встречались характерные признаки для каждой формы. Детальное изучение сосудистых структур позволяет проводить диффреренциальный диагноз с раком in situ. При АК наблюдали точечные и клубочковые сосуды не более чем в 10\% случаев, что помогало дисрфреренцировать АК от рака in situ, при котором подобные сосуды встречались в 40\%. Клубочковые сосуды не встречались в нашем исследовании, а точки отмечали только в 2,45\% случаев. Кератотическая форма характеризовалась в 100\% случаев наличием кератиновых чешуек. При пигментной фрорме мы выявляли темно-коричневые прожилки (80\% случаев), темно-коричневые точки (50\%), коричневые глобулы (30\%), темнокоричневые кляксы (10\%) и шиферно-серые точки (10\%). Но золотым стандартом диффреренциального диагноза со злокачественным лентиго является морфологическое исследование.

Заключение. АК имеет специфические признаки при дерматоскопическом исследовании, которые помогают дифференцировать его от доброкачественных и злокачественных образований кожи, а также диагностировать его на самых ранних стадиях, не прибегая к инвазивным методикам. Эффективная диагностика АК снизит риск злокачественной трансорормации и будет способствовать выбору адекватной и необходимой тактики лечения.

Ключевые слова: актинический кератоз, дерматоскопия, paк in situ.

Контактная инсормация: 89160428216@уаndex.ru. Вестник дерматологии и венерологии 2017; (2): 45—52. 


\title{
iagnosis of actinic keratosis by dermatoscopy
}

\author{
A. N. Khlebnikova', K. V. Obydenova², T. G. Sedova ${ }^{3}$, V.V. Andrukhina ${ }^{2}$
}

${ }^{1}$ I. M. Sechenov First Moscow State Medical University of the Ministry of Health of the Russian Federation Trubetskaya str., 8/2, Moscow, 119991, Russia

${ }^{2}$ MO GBUZ MONIKI im. M. F Vladimirskogo,

Shchepkina str., 61/2, Moscow, 129110, Russia

${ }^{3}$ Perm State Medical University named after E. A. Wagnera (PSMU) of the Ministry of Health of the Russian Federation

Petropavlovskaya str., 26, Perm, 614000, Russia

\begin{abstract}
Introduction: Actinic keratosis (AK) is a local introepidermal atypia of keratinocytes, formed as a result of intense and prolonged exposure to sunlight. AK lesions located on exposed areas of skin, mostly on the face, in this regard, a more relevant non-invasive diagnostic techniques, primarily dermatoscopy.

Material and methods: We examined 35 patients and revealed they have 204 hearth.

Results: Of the 204 lesions erythematous form was found in 160 (78, 4\%) cases, keratotic — 24 (11,8\%), pigmental (9.8 \%).

Patients with AK most private dermatoscopic signs were erythema $(90,2 \%)$, vascular structures $(67,65 \%)$, keratin scales $(51,47 \%)$, pseudonetwork (23,04\%).

Discussion: Analyzing dermoscopic picture of the most common forms of AK met the characteristics for each shape. A detailed study of vascular structures allows for the differential diagnosis of cancer in situ. While AK watched point and the glomerular vessels of not more than $10 \%$ of cases, which helped to differentiate AK from cancer in situ, in which such vessels were found in $40 \%$. Glomerular vessels are not met in our study and the points were only $2.45 \%$ of the cases. Keratotic AK was characterized in $100 \%$ of cases the presence of keratin scales. In pigment form, we revealed the dark brown streaks (80\%), dark brown points (50\%), brown globules (30\%), dark brown blots (10\%) and slate-grey dots (10\%). But the gold standard for the differential diagnosis with maligna lentigo is a morphological study.

Conclusion: AK has specific characteristics in treatment research, which helps to differentiate it from other benign and malignant tumors of the skin, and to diagnose it in its earliest stages without resorting to invasive procedures. Effective diagnosis of AK reduces the risk of malignant transformation and contribute to the selection of adequate and necessary treatment tactics.
\end{abstract}

Key words: actinic keratosis, dermatoscopy, cancer in situ.

Corresponding author: 89160428216@yandex.ru. Vestnik Dermatologii i Venerologii 2017; 2: 45—52. 
Актинический кератоз (синонимы: солнечный кератоз, старческий кератоз) - локальная внутриэпидермальная атипия кератиноцитов разной степени выраженности, обусловленная воздействием солнечных лучей [1]. Очаги поражения развиваются на фоне сухой и гиперпигментированной кожи, стареющей под воздействием солнечного света, и проявляются одиночными либо множественными, сгруппированными, слегка болезненными пятнами или бляшками неправильной фрормы диаметром от 0,3 до 3-5 см (обычно меньше 1 см), покрытыми ороговевающими чешуйками, жесткими, шероховатыми, на ощупь напоминающими грубую наждачную бумагу, спаянными с подлежащей кожей и с трудом отделяющимися от нее (иногда с признаками незначительного кровотечения). Очаги имеют неровные края, розовую или коричневую окраску. В большинстве случаев они локализуются на коже головы (на лице и на волосистой части), шее и на верхних конечностях вследствие того, что эти участки кожного покрова наиболее подвержены воздействию УФ-радиации. У мужчин в процесс нередко вовлекается кожа ушной раковины, у женщин - голени [1]. Клинически выделяют пять форм АК (эритематозную, кератотическую, роговую, папилломатозную, пигментную), которые с течением времени могут трансформироваться одна в другую.

Заболевают АК чаще светлокожие люди со светлым, рыжим или русым цветом волос, имеющие I-II фототип по Фитцпатрику [2]. Появлению очагов АК способствует чрезмерное ультрафиолетовое облучение (УФО) [3, 4], в особенности УФВ-лучи (290-320 нм), что приводит к мутации ДНК кератиноцитов [5]. Постоянное хроническое воздействие УФ-лучей на очаги АК способствует постепенному прогрессированию в плоскоклеточный рак [5]. Пациенты с иммунодефицитом, например, перенесшие трансплантацию органов и соответственно получившие иммуносупрессивную терапию, находятся в группе риска возникновения АK [2]. Кроме того, наличие генетически обусловленных состояний, таких как ксероз кожи, пигментная ксеродерма и альбинизм, может быть предрасполагающим фрактором в развитии АK [6].

Диагноз АК ставится на основании клинической картины и требует гистологического подтверждения [5]. В последнее время набирает популярность такой метод диагностики, как дерматоскопия. Дерматоскопия, также известная как эпилюминисцентная микроскопия, является методикой подробной визуальной интерпретации поражений кожи. Это быстрый, недорогой и, главное, неинвазивный метод диагностики, обеспечивающий дополнительную визуальную информацию при осмотре пациента. [8] Позволяет оценить морфологические структуры эпидермиса, дермоэпидермального соединения и сосочкового слоя кожи, не видимых невооруженным глазом. [9] Этот метод стоит как бы между клиническим и гистологическим исследованиями, т. к. дермато- скопические структуры коррелируют с гистопатологическими изменениями $[9,10]$. Метод позволяет проводить диффреренциальный диагноз доброкачественных и злокачественных, меланоцитарных и немеланоцитарных опухолей кожи [10]. К тому же дерматоскопия помогает контролировать повреждения с течением времени или оценивать ответ на проводимое лечение [8].

Основными дерматоскопическими признаками АK являются эритема, красная псевдосеть (сетчатая структура, образованная сосудами), чешуйки и корки, сосуды, а также составная структура «клубничный узор», которая фрормируется из расширенных нефокусированных сосудов, белого ореола вокруг фолликулов и заполненных роговыми массами устьев волосяных фолликулов. Некоторые дерматоскопические особенности имеет пигментная форма АК. В результате этого большинство исследователей выделяют две группы дерматоскопических признаков, характерных для непигментных и пигментных форм образования [7, 12]. Основная часть исследований посвящена дифференциальной диагностике на основании дерматоскопии непигментных форм АК с внутриэпидермальным раком и плоскоклеточной карциномой и пигментной формы со злокачественным лентиго [12-14]. Подробного анализа дерматоскопических особенностей клинических фрорм АК в литературе мы не встретили. В связи с чем целью нашего исследования явилось изучение дерматоскопических признаков различных клинических форм АК.

\section{Материал и методы}

Под нашим наблюдением находились 35 пациентов в возрасте от 55 до 90 лет, средний возраст $73 \pm 6,06$ года. Давность заболевания составляла от 6 месяцев до 5 лет. 12 пациентов были мужского пола $(34,2 \%)$ и 23 - женского $(65,8 \%)$. У 4 пациентов наблюдался одиночный очаг АК (11,4\%), у 31 - множественные очаги АK (88,6\%). Всего было выявлено 204 очага. Дерматологические изображения получены с помощью дерматоскопа Heine Delta 20 plus и цифровой камеры Nikon. Для статистической обработки данных использовался метод t-Стьюдента с поправкой для множественных сравнений. Расчеты проводились при помощи программы BIOSTAT. Полученные различия считались достоверными при значениях $p<0,05$.

Анализ частот встречаемости качественных признаков проводили с помощью точного критерия Фишера. При сравнении трех групп после первичного сравнения с использованием точного критерия Фишера проводили попарные сравнения, применяя поправку Бонферрони.

\section{Результаты}

Среди 204 очагов эритематозная форма встречалась в 160 (78,4\%) случаях (рис. 1), кератотическая в 24 (11,8\%) (рис. 2), пигментная - в 20 (9,8\%) (рис. 3).

Анализ дерматоскопической картины показал, что наиболее часто встречаемым дерматоскопическим 


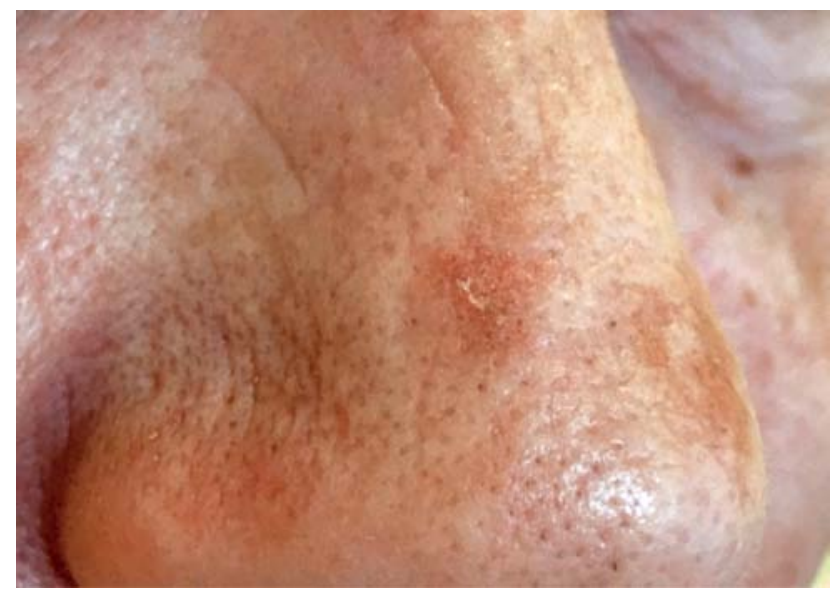

Рис. 1. Эритематозная форма AK

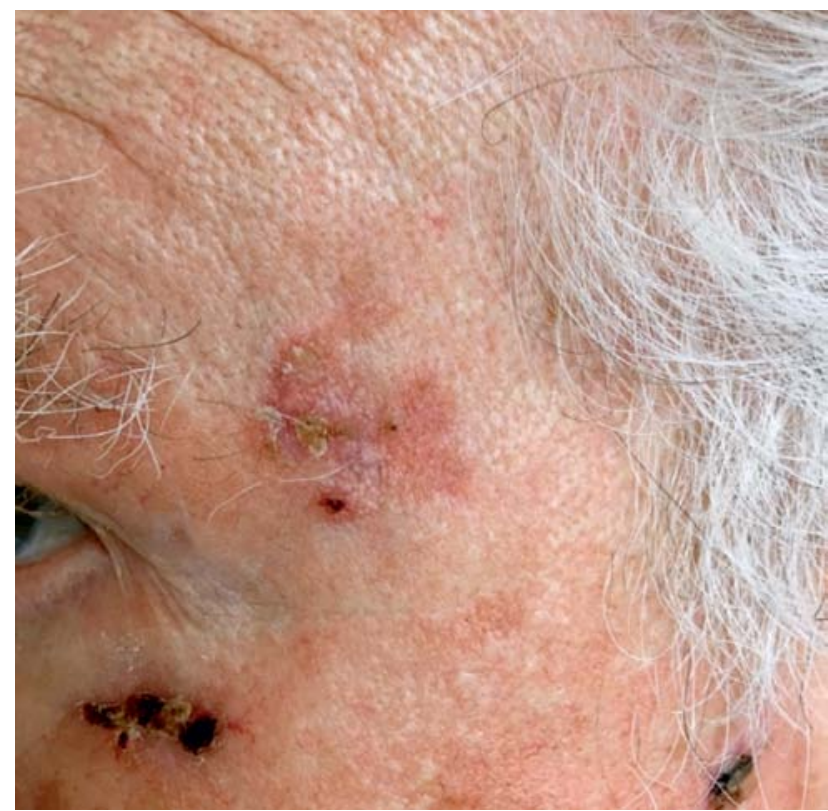

Рис. 2. Кератотическая форма AK

признаком AK независимо от клинической формы является эритема, цвет которой варьировал от бледнорозового до красного. Она встречалась в 184 (90,2\%) случаях. Поверхностные кератиновые чешуйки, цвет которых менялся от белого до желтого, и сосуды, представленные различными разновидностями, наблюдали в 138 (67,65\%) и 105 (51,47\%) случаях соответственно. Кроме того, наблюдали белый ореол вокруг фолликулярных отверстий и очага в 53 (25,98\%) слу-

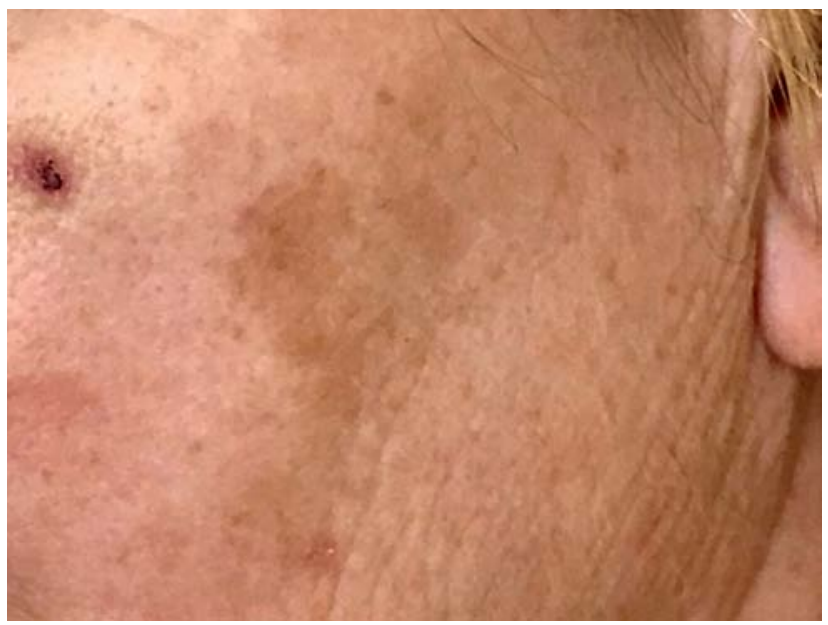

Рис. 3. Пигментная форма АK

чаях, красную псевдосеть - в 47 (23,04\%), нессрокусированные сосуды между фолликулов - в 44 (21,57\%), желтоватые кератотические пробки в расширенных волосяных фролликулах - в 37 (18,4\%), клубничный узор - в 28 (13,73\%), темно-коричневые прожилки в $21(10,29 \%)$ случае. Реже встречались массивные чешуйко-корки, темно-коричневые прожилки и милиоподобные кисты в 14 (6,86\%), 11 (5,39\%) и 9 (4,41\%) случаях соответственно. Остальные признаки (глобулы коричневые, темно-коричневые пятна, кляксы темно-коричневого цвета, шиферно-серые точки, мишеневидные очаги) встречались в единичных случаях.

При детальном изучении сосудистых структур было установлено, что они представлены различными типами сосудов: извитые $(28,43 \%)$, линейные $(15,2 \%)$, древовидные (2,94\%), точечные $(2,45 \%)$. Волнистые сосуды, сосуды в виде клякс и скобок встречались в единичных случаях.

При эритематозной форме АК отмечалась следующая частота дерматоскопических признаков: эритема - 146 (91,25\%) случаев, поверхностные кератиновые чешуйки - 110 (68,75\%), сосуды - 99 (61,88\%), белый ореол вокруг фолликулярных отверстий и вокруг очага - 39 (24,38\%), несфрокусированные сосуды между фолликулами - 34 (21,25\%), клубничный узор - 28 (17,5\%), красная псевдосеть - 27 (16,88\%), желтоватые кератотические пробки в расширенных волосяных фолликулах - 27 (16,88\%), милиоподобные кисты - 9 (5,63\%) случаев. Темно-коричневые прожилки, мишеневидные очаги, темно-коричневые точки встречались в единичных случаях. Среди сосудистых структур отмечали: извитые сосуды - 58 $(58,59 \%)$ случаев, линейные - $27(27,27 \%)$, древовидные - 6 (6,06\%), точечные - $5(5,05 \%)$, в виде кляксы $-2(2,02 \%)$, волнистые - $1(1,01 \%)$ случай. 
При кератотической фрорме чешуйки кератиновые поверхностные от белого до желтого цвета встречались во всех 24 (100\%) случаях. Эритема и массивные чешуйко-корки регистрировались в 22 (91,67\%) и в 14 (58,33\%) случаях соответственно. В 10 случаях $(41,67 \%)$ наблюдали красную псевдосеть, несфокусированные сосуды между фолликулов, белый ореол вокруг фолликулярных отверстий и вокруг очага, желтоватые кератотические пробки в расширенных волосяных фолликулах. Сосуды наблюдали в 4 (16,67\%) случаях, в 2 случаях были линейные сосуды, в 2 других - сосуды в виде скобки. Темно-коричневые пятна и темно-коричневые прожилки были зарегистрированы в 2 случаях (8,33\%).

При пигментной форме АК эритема и темно-коричневые прожилки наблюдали в 16 (80\%) случаях, красную псевдосеть и темно-коричневые точки в 10 (50\%) случаях. Глобулы коричневые, белый ореол вокруг фоолликулярных отверстий и вокруг очага, чешуйки кератиновые поверхностные были выявлены в $6(30 \%), 4$ (20\%), 4 (20\%) случаях соответственно. Сосуды в виде линий, кляксы темно-коричневого цвета, шифрерно-серые точки наблюдали в 2 (10\%) случаях.

Сравнительный анализ дерматоскопических признаков показал, что для эритематозной формы, в отличие от кератотической и пигментной, наиболее характерно наличие поверхностных кератиновых чешуек, которые визуализировались в 68,75\% случаев, сосудов в $61,88 \%$, несфокусированных сосудов между фолликулами - в 21,25\% (таблица) случаев. Следует отметить, что при эритематозной форме встречалось шесть видов сосудов (извитые, линейные, древовидные, точечные, в виде кляксы, волнистые). Наиболее характерными признаками кератотической фрормы явились: поверхностные кератиновые чешуйки (100\% случаев), массивные чешуйко-корки (91,67\%), желтоватые кератотические пробки в расширенных волосяных фолликулах $(41,67 \%)$ (см. таблицу). Дерматоскопическая картина пигментной формы АК характеризуется темно-коричневыми прожилками (80\% случаев), темно-коричневыми точками (50\%), коричневыми глобулами (30\%), темнокоричневыми кляксами (10\%) и шиферно-серыми точками (10\%) (см. таблицу).

\section{Сравнительный анализ дерматоскопических признаков при эритематозной, кератотической \\ Таблица и пигментной формах АК (значения $р$ при попарных сравнениях точным критерием Фишера с поправкой Бонсеррони $(p \cdot 3))$}

\begin{tabular}{|c|c|c|c|}
\hline & $1-2$ & $2-3$ & $3-1$ \\
\hline Чешуйки кератиновые поверхностные от белого до желтого цвета & 0,001 & $<0,001$ & $<0,001$ \\
\hline Красная псевдосеть & 0,033 & $>0,999$ & 0,005 \\
\hline Несфрокусированные крупные сосуды между фолликулами & 0,113 & 0,011 & 0,047 \\
\hline Пробки желтоватые кератотические в расширенных волосяных фолликулах & 0,033 & 0,011 & 0,141 \\
\hline Клубничный узор & 0,084 & 1,000 & 0,138 \\
\hline Массивные чешуйко-корки & $<0,001$ & $<0,001$ & 1,000 \\
\hline Сосуды: & $<0,001$ & $>0,999$ & $<0,001$ \\
\hline \multicolumn{4}{|l|}{ линейные } \\
\hline \multicolumn{4}{|l|}{ извитые } \\
\hline \multicolumn{4}{|l|}{ точечные } \\
\hline волнистые & 0,004 & $>0,999$ & $>0,999$ \\
\hline \multicolumn{4}{|l|}{ древовидно-разветвляющиеся } \\
\hline \multicolumn{4}{|l|}{ кляксы } \\
\hline \multicolumn{4}{|l|}{ скобки } \\
\hline Темно-коричневые пятна & 0,048 & $>0,999$ & 1,000 \\
\hline Темно-коричневые точки & 1,000 & $<0,001$ & $<0,001$ \\
\hline Темно-коричневые прожилки & 0,381 & $<0,001$ & $<0,001$ \\
\hline Глобулы коричневые & 1,000 & 0,016 & $<0,001$ \\
\hline Кляксы темно-коричневого цвета & 1,000 & 0,603 & 0,035 \\
\hline Шиферно-серые точки & 1,000 & 0,603 & 0,035 \\
\hline
\end{tabular}

Примечание. 1 - эритематозная форма; 2 - кератотическая форма; 3 - пигментная форма. 


\section{Обсуждение}

Анализ дерматоскопической картины всех очагов АК независимо от клинической фрормы показал, что эритема различных оттенков встречалась в $90,2 \%$ случаев, несколько реже - в 67,65 и в 51,47\% случаев регистрировали поверхностные кератиновые чешуйки и сосуды соответственно. Кератиновые чешуйки в 79,4 и в $81 \%$ случаев при АК наблюдали и другие исследователи [15]. В то же время одним из самых частых признаков являлась псевдосеть, которую определяли в 95 и 73,5\% случаев [15]. Мы визуализировали красную псевдосеть в 23,04\% случаев, наряду с белым ореолом вокруг фолликулярных отверстий и вокруг очага - 25,98\%, несфокусированными сосудами между фолликулами - 21,57\% и кератотическими пробками в расширенных фолликулах - 18,4\%. Специфричным дерматоскопическим признаком АК является клубничный узор, по данным ряда авторов подобные структуры регистрировали в 95\% случаев [7, 16]. Частота данной структуры в нашем исследовании не превышала $14 \%$, что, возможно, связано с неоднозначной трактовкой тех или иных терминов, более подробным выделением и учетом нами отдельных признаков и их объединением другими исследователями.

Сосуды играют важную роль в дерматоскопической диагностике опухолей кожи. Возрастание количества атипичных сосудов свидетельствует о злокачественном потенциале новообразования [15]. Мы визуализировали 7 разновидностей сосудов при АК: извитые, линейные, древовидные, точечные, волнистые, в виде клякс и скобок. При этом извитые и линейные сосуды встречались наиболее часто в 28,43 и $15,2 \%$ случаев соответственно. Ранее при АК наблюдали точечные и клубочковые сосуды не более чем в 10\% случаев, что помогало диффференцировать АK от рака in situ, при котором подобные сосуды встречались в $40 \%$ случаев [17]. Мы согласны с этим мнением, т. к. клубочковые сосуды не встречались в нашем исследовании, а точки отмечали только в $2,45 \%$ случаев. Отсутствие сосудов в виде шпилек, по нашим данным, в AK помогает диффференцировать его от плоскоклеточного рака, при котором они преобладают [16].

Клинические проявления АК весьма разнообразны, чаще всего встречаются эритематозная, кератотическая и пигментная формы. При их выявлении всегда приходится проводить дифрференциальный диагноз с раком in situ в первых двух случаях либо со злокачественным лентиго в третьем. Поэтому очень важно знать основные дерматоскопические проявления каждой формы АК. Нами было установлено, что для эритематозной формы наиболее характерно наличие поверхностных кератиновых чешуек в $68,75 \%$ случаев, сосудов в $61,88 \%$, несфокусированных сосудов между фолликулами в 21,25\% случаев. Встречалось шесть видов сосудов (извитые, линейные, древовидные, точечные, в виде кляксы, волнистые). Совокупность призна-

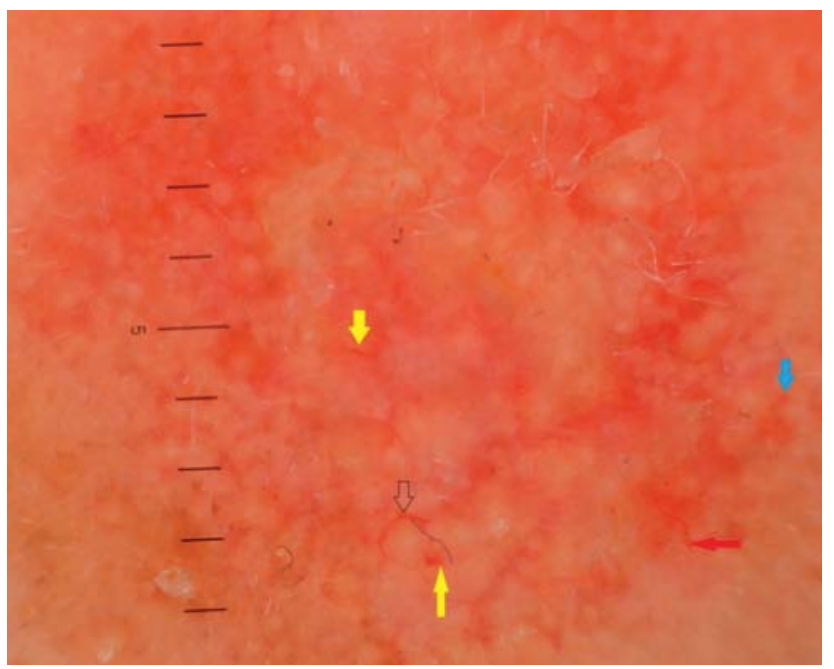

Рис. 4. Сосудистые структуры (дерматоскопическое изображение):

извитые сосуды (черная стрелка), сосудыкляксы (желтая), сосуды-точки (голубая), волнистые (красная)

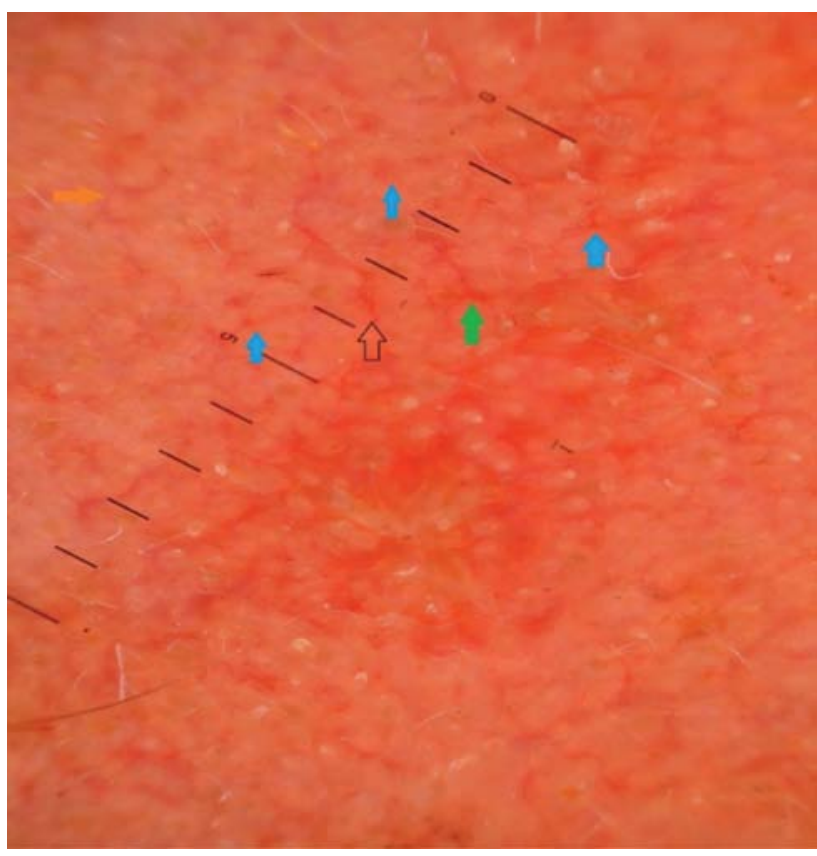

Рис. 5. Сосудистые структуры (дерматоскопическое изображение):

извитые сосуды (черная стрелка), сосудыкляксы (голубая), древовидно-разветвляющиеся (зеленая), сосуды-скобки (оранжевая) 


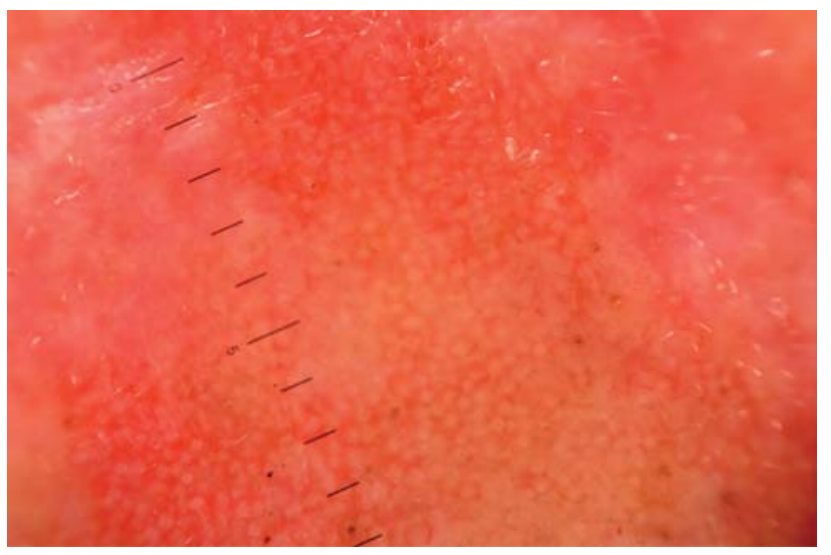

Рис. 6. Клубничный узор (дерматоскопическое изображение)

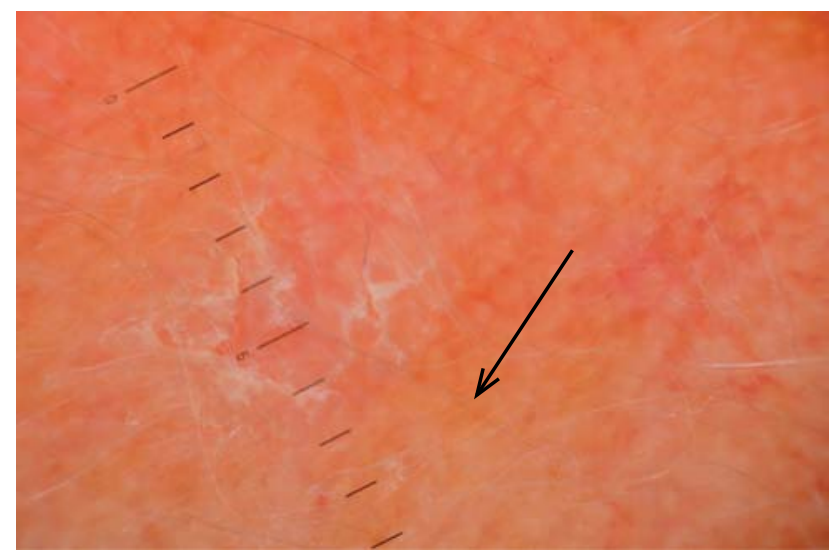

Рис. 7. Дермоскопическая картина эритематозной формы AK.

На фооне эритемы расположены нежные кератиновые чешуйки белого цвета (указаны стрелкой)

ков, а также разнообразие сосудов и отсутствие среди них клубочков позволяет отличать на основе дерматоскопического исследования AK и рак in situ. Кератотическая фрорма характеризовалась наличием кератиновых чешуек (100\% случаев), массивных чешуйко-корок $(91,67 \%)$ и желтоватых кератотических пробок в расширенных волосяных фолликулах $(41,67 \%)$, при этом только в $16,67 \%$ случаев встречались сосуды в виде линий и скобок. Следует подчеркнуть, что при раке in situ ведущим признаком является наличие клубочковых сосудов, а кератотические пробки в расширенных волосяных фолликулах не встречаются [17]. При пигментной форме мы выявляли темно-коричневые прожилки (80\% случаев), темно-коричневые точки (50\%),

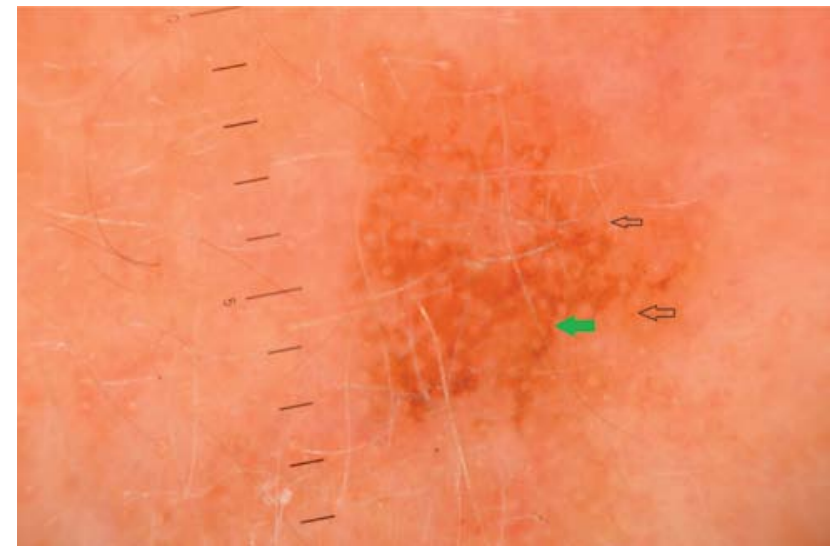

Рис. 8. Дерматоскопическая картина пигментного AK.

На фоне бледно-розовой эритемы видна псевдосеть, образованная белыми округлыми очагами и коричневыми прожилками (зеленая стрелка), также видны отдельные точки коричневого цвета (черная стрелка)

коричневые глобулы (30\%), темно-коричневые кляксы (10\%) и шиферно-серые точки (10\%). Большинство исследователей сходятся во мнении, что основным признаком пигментного АК являются серые точки, которые наблюдали в 94,1 и 70\% случаев [18], а также коричневые точки/глобулы и коричневую псевдосеть [7]. Серые точки выделяют как основной дифференциально диагностический признак между пигментным АК и злокачественным лентиго, при котором этот признак встречался только в 23,8\% случаев [18]. Хотя другие авторы подчеркивают, что пигментный АК и злокачественное лентиго имеют схожую дерматоскопическую картину, а золотым стандартом диагностики остается морфологическое исследование [12].

\section{Заключение}

Дерматоскопическая картина АК характеризовалась наличием эритемы в 90,2\% случаев, поверхностных кератиновых чешуек в $67,65 \%$ и сосудов в 51,47\% случаев. Реже наблюдали белый ореол вокруг фолликулярных отверстий и вокруг очага (25,98\% случаев), красную псевдосеть (23,04\%), несфокусированные сосуды между фолликулами (21,57\%), желтоватые кератотические пробки в расширенных волосяных фолликулах (18,4\%), клубничный узор (13,73\%), темно-коричневые прожилки (10,29\% случаев).

Сосудистые структуры при АК были представлены 7 типами сосудов: извитые, линейные, древовидные, точечные, волнистые, в виде клякс и скобок. Наиболее часто визуализировали извитые и линейные сосу- 
ды (в 28,43 и 15,2\% случаев соответственно), значительно реже - древовидные и точечные (2,94 и 2,45\% соответственно). Волнистые сосуды, сосуды в виде клякс и скобок встречались в единичных случаях.

Сравнительная оценка частоты дерматоскопических признаков в различных клинических фрормах АК показала, что при эритематозной форме чаще встречаются поверхностные кератиновые чешуйки $(68,75 \%$, $p<0,001)$ и сосуды $(61,88 \%, p<0,001)$; при кератотической форме - поверхностные кератиновые чешуйки $(100 \%, p<0,001)$, массивные чешуйко-корки $(91,6 \%, p<0,001)$ и желтоватые кератотические пробки в расширенных волосяных фолликулах $(41,67 \%$, $p<0,05)$; при пигментной - темно-коричневые прожилки $(80 \%, p<0,001)$, темно-коричневые точки (50\%, $p<0,001)$, коричневые глобулы $(30 \%, p<0,01)$.

\section{Литература}

1. Молочков В.А., Молочков А. В. Клиническая дерматоонкология. М.: Из-во студия МДВ, 2011. 340 с., илл., табл. с. 74, 75. Molochkov V. A., Molochkov A. V. Klinicheskaya dermatoonkologiya. M.: Iz-vo studiya MDV, 2011. 340 s., ill., tabl. s. $74,75$.

2. Claudia Costa, Massimiliano Scalvenzi, Fabio Ayala, Gabriella Fabbrocini, Giuseppe Monfrecola. How to treat actinic keratosis? An update. Department of Dermatology, Federico II University, Naples, Italy. J Dermatol Case Rep 2015; 2: pp 29-35.

3. Annabel Dodds, Alvin Chia, Stephen Shumack. Actinic Keratosis: Rationale and Management. Dermatol Ther (Heidelb) 2014; 4: 11—31.

4. Traianou A., M. Ulrich, Z. Apalla, E. De Vries, K. Bakirtzi, D. Kalabalikis, L. Ferrandiz, A. Ruizde-Casas, D. Moreno-Ramirez, D. Sotiriadis, D. Ioannides, S. Aquilina, C. Apap, R. Micallef, L. Scerri, S. Pitkanen,0. Saksela, E. Altsitsiadis, B. Hinrichs, C. Magnoni, C. Fiorentini, S. Majewski, A.Ranki,C. M. Proby,E, Stockfleth and M. Trakatelli on behalf of the EPIDERM Group. Risk factors for actinic keratosis in eight European centres: a case-control study, British Association of Dermatologists 2012; 167 (Suppl. 2), pp 36-42.

5. Marina Câmara de Oliveira, Flávia Trevisan, Clovis Antônio Lopes Pinto, Célia Antônia Xavier, Jaqueline Campoi Calvo Lopes Pinto. Histopathological analysis of the therapeutic response to cryotherapy with liquid nitrogen in patients with multiple actinic keratosis. An Bras Dermatol 2015; 90 (3): 384—9.
6. Caterina Longo, Stefania Borsari, Elisa Benati Elvira Moscarella, Roberto Alfano, Giuseppe Argenziano. Dermoscopy and Reflectance Confocal Microscopy or Monitoring the Treatment of Actinic Keratosis with Ingenol Mebutate Gel: Report of Two Cases. Dermatol Ther (Heidelb) 2016; 6: 81—87.

7. Ketty Peris, Tamara Micantonio, Domenico Piccolo, Maria Concetta Fargnoli Dermoscopic features of actinic keratosis Department of Dermatology,University of L'Aquila, L'Aquila, Italy JDDG; 2007; 5: 970—976.

8. Thomas D. Butler, Rubeta N. Matin, Andrew G. Affleck, Colin J.Fleming, Jonathan C. Bowling. Trends in dermoscopy use in the UK: results from surveys in 2003 and 2012. Dermatol Pract Concept 2015; 5 (2): 4.

9. Teresa Russo, Vincenzo Piccolo, Aimilios Lallas, Giuseppe Argenziano. Recent advances in dermoscopy 2016, 5 (F1000 Faculty Rev): 184 Last updated: 17 FEB 2016

10. Frost C.A., Green A.C. Epidemiology of solar keratoses. Br J Dermatol. Oct 1994; 131 (4): 455-464.

11. Yana Goncharova, Enas A. S. Attia,Khawla Souid, and Inna V. Vasilenko. Dermoscopic Features of Facial Pigmented Skin Lesions. Hindawi Publishing Corporation ISRN Dermatology Volume 2013: 1-7.

12. Akay B. N., Kocyigit P., Heper A. O. and Erdem C. Dermatoscopy of flat pigmented facial lesions: diagnostic challenge between pigmented actinic keratosis and lentigo maligna. Departments of Dermatology and Pathology, University of Ankara School of Medicine, Samanpazari 06100, Ankara, Turkey.
13. Iris Zalaudek, Jason Giacomel, Karin Schmid, Silvia Bondino, Cliff Rosendahl, Stefano Cavicchini, Athanasia Tourlaki, Saturnino Gasparini, Peter Bourne, Jeff Keir, Harald Kittler, Laura Eibenschutz, Caterina Catricala, and Giuseppe Argenziano. Dermatoscopy of facial actinic keratosis, intraepidermal carcinoma, and invasive squamous cell carcinoma: a progression model. J AM ACAD DERMATOL APRIL 2012: 590-596.

14. Ulrich M, Zalaudek I, Welzel J. Shining into the White: The Spectrum of Epithelial Tumors from Actinic Keratosis to Squamous Cell Carcinoma. Dermatol Clin. 2016 Oct; 34 (4): 459_467.

15. Iris Zalaudek, Jurgen Kreusch, Jason Giacomel, Gerardo Ferrara, Caterina Catricala, Giuseppe Argenziano. How to diagnose nonpigmented skin tumors: A review of vascular structures seen with dermoscopy Part I. Melanocytic skin tumors. J AM ACAD DERMATOL SEPTEMBER 2010: 361-373.

16. Zalaudek J., Giacomel G., Argenziano R., HofmannWellenhof T., Micantonio A., Di Stefani M., Oliviero H., Rabinovitz H., Soyer P. and Peris K. Dermoscopy of facial nonpigmented actinic keratosis. British Journal of Dermatology 2006; 155: 51—956.

17. Iris Zalaudek, Jurgen Kreusch, Jason Giacomel, Gerardo Ferrara, Caterina Catricala, Giuseppe Argenziano, P. D. Graz. How to diagnose nonpigmented skin tumors: A review of vascular structures seen with dermoscopy Part II. Nonmelanocytic skin tumors. J AM ACAD DERMATOL SEPTEMBER 2010: 378-386.

18. Mauricio M. Nascimento, Danielle Shitara, Milvia M.S. S. Enokihara, Sergio Yamada, MD,Giovanni Pellacani, Gisele G. Rezze. Inner gray halo, a novel dermoscopic feature for the diagnosis of pigmented actinic keratosis: Clues for the differential diagnosis with lentigo maligna. J AM ACAD DERMATOL: 71 (4): 709—715.

об авторах:

А. Н. Хлебникова - д.м.н., профрессор, профессор кафедры кожных и венерических болезней ФГАОУ ВО Первый МГМУ им. Сеченова И. М. Минздрава России (Сеченовский университет), Москва

К. В. Обыденова — научный сотрудник отделения планирования и координации научных исследований ГБУЗ МО МОНИКИ им. М. Ф. Владимирского, Москва

Т. Г. Седова - к.м.Н., доцент касредры дерматовенерологии ГБОУ ВПо Пермский ГМУ им. академика Е. А. Вагнера

В.В. Андрюхина — к.м.Н., научный сотрудник отделения челюстно-лицовой хирургии ГБУЗ МО МОНИКИ

им. М. Ф. Владимировского, Москва

\section{Конфликт интересов}

Авторы заявляют об отсутствии потенциального конфрликта интересов, требующего раскрытия в данной статье 